\title{
Cross-Border Collaboration in River Management: Views on Participation in a Dutch-German Case Study
}

\author{
Katharina Panten ${ }^{1}$ - Bernadette F. van Heel ${ }^{1}$. \\ Jan M. Fliervoet ${ }^{1,2}$ • Riyan J. G. van den Born ${ }^{1}$
}

Received: 20 December 2017 / Accepted: 9 July 2018 /

Published online: 16 July 2018

(C) The Author(s) 2018

\begin{abstract}
Integrated river basin management (IRBM) calls for participatory practices involving stakeholders along transnational river landscapes. Understanding the complex and diverse views regarding participation is a prerequisite for meaningful involvement of civil actors, especially in a transnational context. In a case study along the Lower Rhine river, we assessed and compared cognitive perceptions towards IRBM of citizen initiatives and nature organizations from Germany and the Netherlands and their previous experiences with participation processes.

We found large differences between the four actor groups in motivations to participate as well as in levels of trust towards institutions. This study also showed different views on participation between the two countries with regard to the problem definition, nature images and the perceived relationships between government organisations on the one hand and citizen initiatives and nature organisations on the other hand.

The findings suggest that views vary between citizen initiatives and nature organizations within a country and that cultural notions add to the complexity of transnational participation. In transnational participation processes, the varying views between actor groups should be taken into account, as well as the complexities among countries even within actor groups.
\end{abstract}

Keywords Integrated river basin management Participation - Transnational collaboration · Visions of nature $\cdot$ Cultural differences

Electronic supplementary material The online version of this article (https://doi.org/10.1007/s11269-0182039-9) contains supplementary material, which is available to authorized users.

Riyan J. G. van den Born

Riyan.vandenborn@ru.nl

1 Institute for Science in Society, Faculty of Science, Radboud University, Nijmegen, Netherlands

2 Applied Research Center Food and Dairy, Sustainable Water Systems, Van Hall Larenstein University of Applied Sciences, Leeuwarden, Netherlands 


\section{Introduction}

Rivers form fluvial connections between inhabited landscapes and ecological habitats, and provide waterways for economic and leisure purposes within and between countries. Climate change continuously poses challenges for management of these multifaceted landscapes (Bormann et al. 2012). Integrated management of river landscapes simultaneously deals with surface and ground waters, urban and riverine drainage and discharge, water quality and provision of drinking water (Junier and Mostert 2012; van Eerd et al. 2014; Wang et al. 2015). The transboundary character of riverine landscapes creates discrepancies between upstream and downstream interests, adding to the management complexities (Wiering et al. 2010). Integrated river basin management (IRBM) aims to address this complexity and benefit society, economy and nature while considering interests of all involved countries along the river basin (Rijke 2012; Wang et al. 2015; Wiering et al. 2010).

To understand and address societal needs, participatory and collaborative approaches lie at the core of IRBM, aiming to involve all layers of society in decision-making processes (Albrecht 2013; Joint Nature Conservation Committee 2010). Such approaches have various opportunities for better informed and creative decision-making, increased public problem awareness and commitment, and social learning (Mostert 2003a; Siddiki et al. 2017) which in turn can foster trust in institutions (Hulbert and Gupta 2015) and their decision-making (Mostert 2003a; Reed 2008). Especially the implementation of projects is difficult if major public stakeholder groups are excluded from the planning stage (Wiering et al. 2010). Participation, however, is challenging. Governmental structures may not yet be adapted to participatory forms of governance, and the complexity, uncertainty and large number of stakes and interests in IRBM are difficult to accommodate within individual projects (Hulbert and Gupta 2015). In addition, a multitude of views towards participation prevail among the public, indicating that 'the public' as a homogenous actor group does not exist. The transnational character of IRBM increases this complexity regarding cultural and political views. For successful participation, it is crucial to understand the actors' views towards participation, their motivations to get involved in projects, and their expectations regarding the process and its outcomes.

Research on policy discourses and perceptions of governmental actors in transnational water management has been performed (Renner et al. 2017; Renner and Meijerink 2017; Wiering et al. 2010; van Eerd et al. 2017) however, little in-depth research on perceptions of public stakeholder groups in relation to factors for successful participation in IRBM exists, especially regarding transnational projects in border regions. Our research aims to fill this knowledge gap by focussing on two public stakeholder groups, i.e. citizen initiatives and nature organizations based in the transnational setting of the crossborder region Rhine-Waal, and assess the differences between actor groups and between countries. Our research thus provides new insights into a variety of perceptions and discourses that civil actors and their international counterparts hold, and adds new understanding to the complexity that transnational participation in IRBM holds. We do so by comparing cognitive perceptions, experiences in participation and the factors trust, motivations and expectations. Perceptions include the actors' argumentative frames (Dewulf et al. 2009), cultural belonging (Mostert 2003b; Thompson 2003) and visions of nature (van den Born 2008). Subsequently, we address opportunities and obstacles these views pose for cross-border collaboration in IRBM. 


\section{Theoretical Framework}

In this paper, we dive into cognitive perceptions and frames (paragraph 2.1) and previous experiences (paragraph 2.2) to understand the underlying drivers of successful participation like the actors' motivations, trust and project expectations (paragraph 2.3), see Fig. 1.

\subsection{Cognitive Perceptions}

Cognitive perceptions are frames that actors use to make sense of a situation (Creed et al. 2002). In negotiation and conflict situations such as in IRBM, actors distinguish and argue within three types of cognitive frames: issue frames, identity and relationship frames, and process frames (Dewulf et al. 2009). With respect to IRBM, the issue frames define the problem that is (or should be) addressed by river management, the identity and relationship frames define what roles and responsibilities civil actors (want to) play, and the relationships they (desire to) have with each other. Lastly, the process frames define how the collaborative process is (or should be) designed and executed. Arguing from different frames has been shown to lead to conflict, as actors cannot empathize with or understand each other's views (Lewicki et al. 2003). Exploring different frames in participation can thus help to align frames to reach common goals.

Additionally, cultural belonging, i.e. a group's habits, traditions and beliefs and political orientation influences views towards participation (Antonini et al. 2015; Hofstede 2011; Mostert 2003a). National cultural core values such as the degree of masculinity, feeling of collectivism and risk adversity influence participatory views (Hofstede 2011). Germany is a country whose political landscape is shaped through formal and impersonal procedures, while in the Netherlands political decisions are resolved through negotiation and compromise (Hofstede 2011; Mostert 2003a). In the case of IRBM, however, it is worthwhile to assess subcultural notions rather than an overall national culture, since national cultures are too



\footnotetext{
Factors for successful participation

- Motivations (Andrews et al. 2005)

- Trust (Hulbert and Gupta 2015)

- Project expectations (Mostert 2003a)
}

Fig. 1 Synthesis of cognitive perceptions, experiences and factors for successful participation 
simplistic to assess various potential actor groups in river management (Thompson 2003). Thompson (2003) describes four such subcultures; fatalist, hierarchist, egalitarian and individualistic (Table 1). Mostert (2003a, 2003b) describes that democracies and their notions as found in subcultures, indicate how actors might approach participation. For instance in egalitarian groups, discussion can disrupt harmony.

In addition to the cognitive perceptions regarding participation and culture, we assess perceptions of nature, which also differ between (sub)cultures. Views on balance in nature influence perceptions of nature's resilience towards human action (Table 1). The concept of visions of nature was developed to assess perceptions of nature, and encompasses (1) the image of nature, i.e. what 'real' nature is; (2) the value of nature, i.e. the values attached to it; and (3) the human-nature relationship, i.e. how humans and nature should relate to each other (van den Born 2008). The images of nature and the human-nature relationship (assessed on the Humans and Nature (HaN) scale; Table SD1) are studied as they are especially important for nature management. The HaN scale distinguishes four relationships with nature: mastery over nature, stewardship of nature, partnership with nature and participation in nature (van den Born 2008).

\subsection{Experiences}

Cognitive perceptions, cultural belonging and views on nature are relatively stable and only change over time e.g. when experiences do not match the previously set cognitive frame (Dewulf et al. 2009). Experiences can thus explain reasoning behind participatory views and shape how actors react in similar situations in the future. Prior participation in governance processes can foster civic attitudes and feelings of political empowerment (Hooghe 2003),

Table 1 Balance in nature representations (based on Thompson 2003; Fliervoet et al. 2013)

\begin{tabular}{|c|c|c|c|}
\hline $\begin{array}{l}\text { Balance } \\
\text { in nature }\end{array}$ & Description as used in this research & Subculture & Visual representation \\
\hline Indifferent & $\begin{array}{l}\text { Nature neutral to human action. } \\
\text { Human action might alter nature, but it } \\
\text { will continue to exist }\end{array}$ & Fatalist & \\
\hline Buffered & $\begin{array}{l}\text { Nature affected by humans but is } \\
\text { stable until certain limits are reached. } \\
\text { If reached, change is irreversible }\end{array}$ & Hierarchist & \\
\hline Unstable & $\begin{array}{l}\text { Human influence on nature is severe - } \\
\text { nature cannot return to initial state }\end{array}$ & Egalitarian & \\
\hline Stable & $\begin{array}{l}\text { Nature always able to return to initial } \\
\text { state, independent of human action }\end{array}$ & Individualist & \\
\hline
\end{tabular}


affecting potential motivations for participation. On the other hand, a prehistory of conflict is likely to cause a lack of trust in future collaboration (Ansell and Gash 2008).

\subsection{Factors for Successful Participation}

One of the factors for successful participation in IRBM is the cooperation of different stakeholders. Creating a dialogue between actors is vital to promote social learning, problem frame alignment and trust building (Mostert et al. 2007). Understanding and addressing factors for successful participation such as the participants' motivations, trust between actors (Hulbert and Gupta 2015; Mostert et al. 2007) and project expectations is thus vital for meaningful actor involvement. Motivations to participate in environmental governance and action can be manifold, ranging from concern for the environment to the desire to contribute to society (Andrews et al. 2005). For successful participation, understanding and acknowledge participants' motivations is essential. Meeting all actors' motivations and expectations towards timing, scope and scale of a project and level of involvement is hardly feasible in complex settings. Transparency about the aspects that can't be met is needed to stimulate trust and prevent disillusionment. This fosters cooperation, which in turn promotes trust and social learning through collaboration (Mostert et al. 2007). While some scholars have argued that trust between participants and institutions is a prerequisite for public participation (Kim 2010; de Vente et al. 2016) others have shown that a lack of trust can motivate civil actors to participate in environmental governance to influence decisions (Antonini et al. 2015; Verbrugge et al. 2017). Issues with greater complexity, such as IRBM, require higher levels of trust between actors to facilitate social learning (Hulbert and Gupta 2015).

\section{Method}

\subsection{Case Study: Lower Rhine River}

The study was conducted in the cross-border region Rhine-Waal, involving Dutch and German civil actors. The area's river management developments are, inter alia, the two dike rings 42 and 48, partly located in North-Rhine Westphalia (G) and Gelderland (NL) (Fig. 2). Even though the dikes are shared, their flood standards differ: 1/1250 years in The Netherlands versus $1 / 500$ or $1 / 100$ years in Germany (van Eerd et al. 2014). The borders of the study area are neither entirely fixed nor limited to the two dike rings as upstream and downstream interests exist and influence riverine management (van Eerd et al. 2014; Wiering et al. 2010). With the banks of the Rhine being densely populated (500 people $/ \mathrm{km}^{2}$ in NorthRhine Westphalia) and industrialized (Thomas and Knüppe 2016) and the river being one of the busiest shipping routes in Western Europe (600 ships/day at the German-Dutch border) (CCNR 2016) climate change poses enormous threats to both economy and society, making climate adaptation a necessity.

\subsection{Research Approach and Respondents}

Civil actors' involvement in transnational IRBM projects has not been the focus of many studies, in contrast to governmental actor involvement (Renner et al. 2017; Renner and Meijerink 2017; Wiering et al. 2010; van Eerd et al. 2017). Hence, little insight is available 


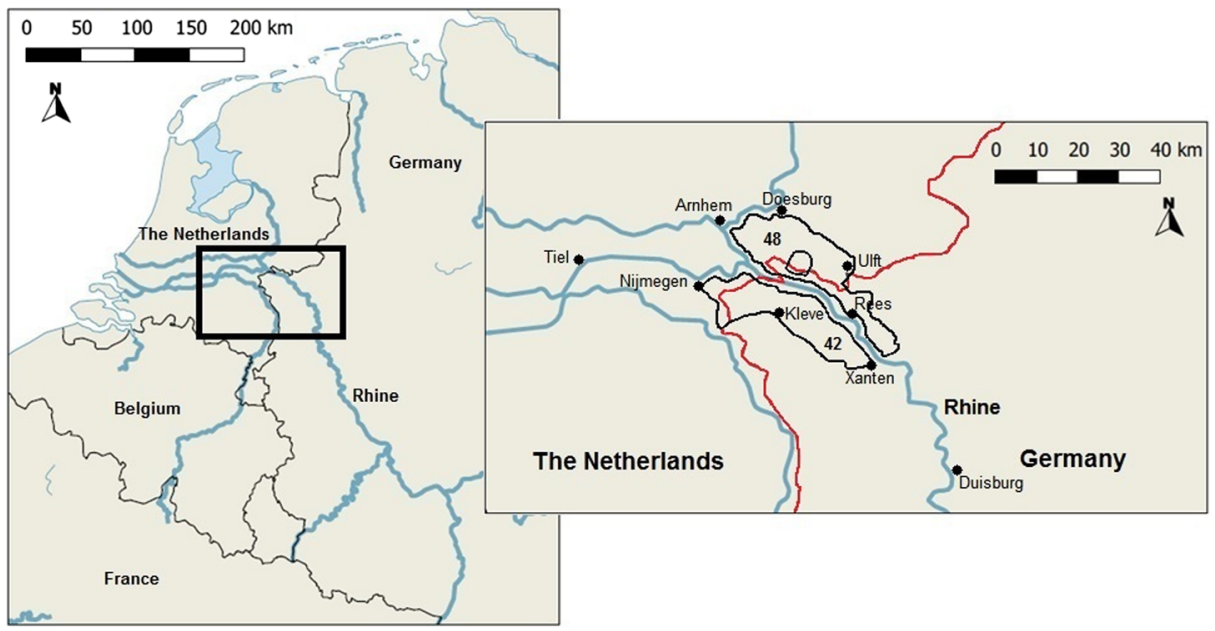

Fig. 2 General study area (left) and detailed location of the Dutch-German border in red, the dike rings 42 and 48 in black and the Rhine river in blue (right).

into the perceptions, discourses, and the potential benefits and obstacles of transnational cooperation of the public in water management. In this research we thus focus on civil actors and try to explore their views to facilitate an early involvement in policy processes. We included citizen initiatives (CIs) and nature organizations (NOs), with an actor distribution of three German CIs, three Dutch CIs, four German NOs and three Dutch NOs. Only actors organized in initiatives or organisations were addressed in this research as they were more likely to have interest, knowledge and capacity to participate in river management (Mostert et al. 2007). The first selection of actors was based on previous research on actors with regard to river management in the crossborder region (Smits 2009). Further organizations and initiatives were searched online.

Due to the exploratory nature of the research, a qualitative research approach of semistructured interviews (paragraph 3.3) was employed (Rubin and Rubin 1995), allowing investigation of perceptions and experiences. Participants were invited to participate in an hour-long interview, conducted by the first author between April and June 2016, to capture their perceptions. Visual representations were integrated into the data collection, to get additional insights on cultural belonging and nature perception.

\subsection{Interview Guide and Visual Representations}

The interview guide was made up of five parts, each with a theme and overarching question(s): (1) personal and working background, such as education and employment; perceptions of nature; and connection to the river Rhine [How is your connection to the Rhine-Waal region? What aspects of the river landscape are of value to you?] (2) personal and (3) professional experiences in river management [What experiences do you have as a citizen/professional with participation in water management?] (4) perceptions of transnational collaboration and cultural differences as well as river management differences [What experiences do you have with transnational collaboration in water management? What is according to you most challenging in transnational settings? What cultural differences do you perceive between the Dutch and the Germans?]; (5) future visions, opportunities and obstacles for transnational collaboration [What future expectations do you have for participation in water management in this region?]. 
To determine nature perception, interviewees were asked to pick the visualisations that represent their view on balance in nature and human-nature relationship (both the most realistic and the most desirable) and explain their reasoning.

\subsubsection{Data Analysis}

With the aim to understand subjective meanings, interviews were transcribed and analysed through content analysis using thematic coding in Atlas.ti (Atlas.ti 2016) (Rubin and Rubin 1995). Transcripts were analysed on a theoretical rather than a descriptive level and major thematic ideas were identified (Gibbs 2007), allowing the categorization of the narratives into different themes. These categories were used as codes, which provided the system of analysis (Gibbs 2007). The framing theory provided three preliminary codes: the issue frames, the identity frames (including roles and relationships) and the process frames (Dewulf et al. 2009). Other aspects were coded according to questions formulated in the interview guide or through open coding. Data of visual representations was counted and compared between actor groups and countries.

\section{Results}

The results are discussed thematically: cognitive perceptions, experiences with participation and factors for successful participation. See Table 2 for a schematic overview.

\subsection{Cognitive Perceptions}

Cognitive perceptions regarding river management were studied through issue frames, identity frames and process frames.

\subsubsection{Issue Frame}

The issue was defined differently across actor groups and countries. For most actors from citizen initiatives, issues related to flooding posed the main concern, while nature organisation members focused on the integration of multiple aims such as flood protection, river naturalness and biodiversity. Dutch civil actors were primarily concerned on local scales, affected by specific river management projects, such as the Varik-Heesselt bypass and the Ooijpolder emergency polder. They did not generally oppose Dutch flood protection strategies. On the contrary, German citizen initiatives opposed the governmental inactivity and lack of strategy rather than specific projects. Nature organisations in both countries were not concerned with local areas but with issues and appropriate measures on larger scales. While Dutch nature organisations focussed on projects such as Room for the River, German organisations had a stronger focus on nature development. They mentioned the avian fauna protection as a priority, and evaluated their success according to the (lack of) achievements of the Water Framework Directive.

\subsubsection{Identity Frame}

The two actor groups show a similar identity frame with direct participation in governance processes: from an organisational standpoint, nature organisations perceived themselves as facilitators of citizen involvement, and citizen initiatives as representatives of local opinions. 
ป

ฮิ

空

过

홍

흘

童

:

물

ڤิ

.

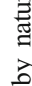

.

⿳亠丷厂

흥

อ

है

莡

ब

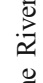

흔

它

ฐี

을

幽

\&

్ㅗㅀ

웡

跑

等

政

욜

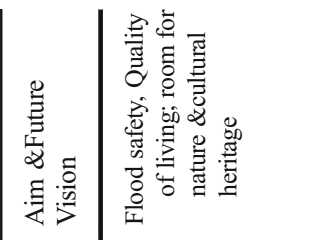

ฐ్

䈉高

핟현

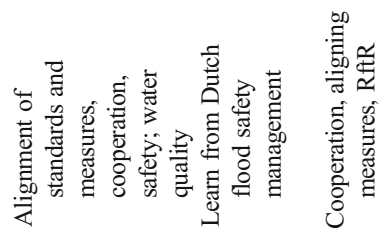

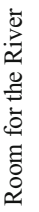

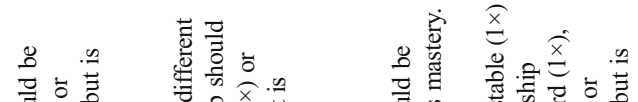

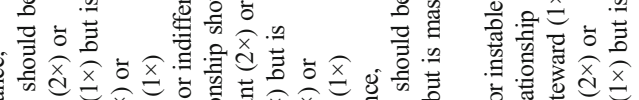

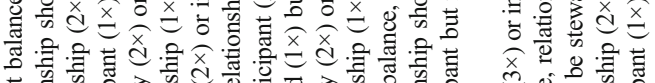

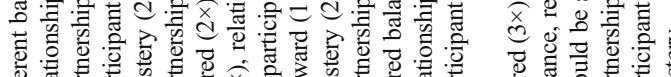

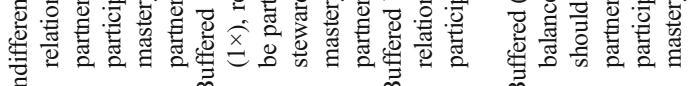

(1)

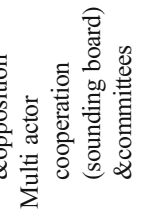

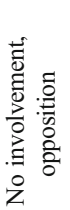

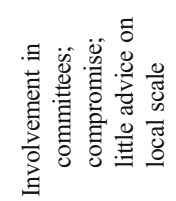

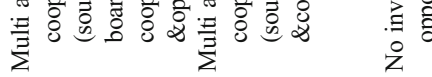

:

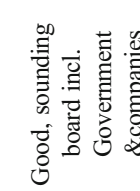

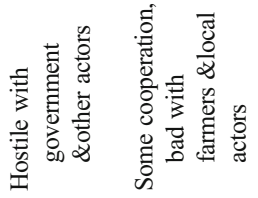

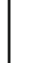

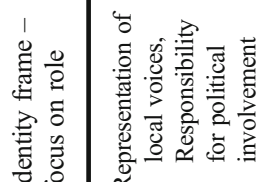

$\frac{8}{2}$

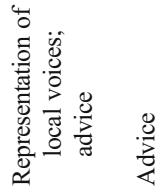

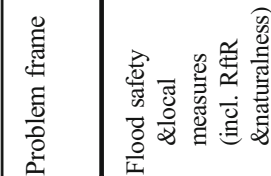

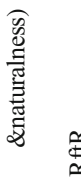

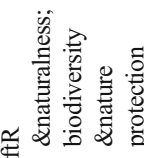

$\overbrace{z} \stackrel{m}{=}$

$\underset{U}{\stackrel{m}{=}} \stackrel{O}{\because} \stackrel{+}{=}$ 
Their direct involvement was aimed at influencing decisions made by the responsible authorities. The actors felt that the responsibility to provide flood safety was a national (or at least federal) one, since different interest groups, such as public authorities, citizens and (agricultural) businesses would otherwise oppose each other's plans. As most of the riverine landscape was already allocated, only a top-level authority could prevent deadlock situations. While in the Netherlands, such a national responsibility is manifested in Rijkswaterstaat and the water boards, platforms such as the sounding board of the Waal were perceived to allow fruitful bottom-up cooperation of stakeholders and create win-win situations. The sounding board includes citizens and NGOs, knowledge institutes and companies and is in lively contact with governmental authorities. While it is not mandatory for the government to act on the group's advice, most interviewees perceived the group's influence as positive: sand extraction companies were involved in Room for the River projects and farmers allowed cyclic flooding and benefited from ecotourism.

In Germany, strong opposition of citizen initiatives against governmental strategy and inactivity provided potential for conflict. Accordingly, the civil actors' perception was characterised by frustration. Due to a lack of platforms for negotiation and communication, actors felt that German authorities showed a lack of transparency and interest. Furthermore, German interviewees generally perceived a conflict of interests with public authorities, and other stakeholders. For instance, they criticized dike associations for being run by local volunteers with local interests, elected by landowners, thus giving farmers with large amounts of land the most elective power. Farmers were perceived to hold traditional farming views with no room for integrated measures. Some German actors from both nature organisations and citizen initiatives criticized the bureaucratic system which led to complications and deadlock situations even among different levels of governmental authorities. According to them, too often, local politicians tried to protect the 'status quo' in their area to gain popularity with local citizens, work against federal authorities and oppose local implementation measures. Nature organisations mentioned that they had to purchase land from businesses or authorities to be able to implement measures.

\subsubsection{Process Frame}

These perceived relationship issues correspond with perceptions regarding the process frame. Actors generally desired a form of direct involvement in the decision-making processes, with a combination of top-down and bottom-up approaches. In the Netherlands, the sounding board for the Waal was an important participatory platform almost all interviewees mentioned. Interviewees were unaware of such collaborative platforms in Germany. Most German interviewees stated that citizens could only be involved in a planning approval procedure (Planfeststellungsverfahren) to raise concerns regarding existing plans, once these were published in the town hall. No possibility for citizens to influence plans at earlier stages was mentioned, making citizens play an opposing rather than a visioning or knowledge contributing role. While German nature organisations mentioned being invited to participate at round tables early on in river management processes e.g. for the implementation of the Water Framework Directive, citizens were not involved.

\subsubsection{Cultural Belonging and Views on Nature}

Cognitive perceptions concerning cultural belonging and nature views were also addressed. The interviews first addressed perceived cultural differences between the two countries in a 
qualitative manner. Due to the proximity of the two countries, all interviewees had interacted with the other culture to a certain extent. Most Dutch participants mentioned differences between the cultures of the countries, especially regarding the 'ways of doing' and management styles: aspects such as more progressive Dutch and more reactive German mindsets and the German procedural accuracy, compared to trial-and-error-approaches of the Dutch, were mentioned. Dutch interviewees also perceived Germans to follow hierarchical structures, and be more conservative and risk adverse which could lead to reactive management styles. The Dutch perceived themselves to be more innovative, risk taking and proactive. One Dutch interviewee, working in Germany, stated that the mindset of German citizens in the crossborder region Rhine-Waal was less advanced and globalized compared to larger German cities. The interviewee perceived most citizens to show backwards thinking and be closely connected to their 'home clubs' (Heimatvereine), which for instance supported traditional farming methods. They were perceived to oppose change and seemed to have little trust in the government, which made cooperation with them difficult. The German interviewees agreed with the Dutch perception that German hierarchical structures and reactive mind-sets were often a hindrance leading to inactivity regarding flood safety. German nature organisations also perceived little innovative projects such as the Dutch Room for the River.

The cognitive perceptions of what nature is, differed between the countries: while many Dutch interviewees perceived 'everything' around them as nature, Germans perceived the landscape around them as 'cultural' and regarded only wild and pristine nature, like a rainforest, as real nature. For them, real nature was nearly impossible to find in the crossborder region.

The balance in nature perception showed consensus among German interviewees: six out of seven German interviewees preferred the buffered model reasoning that human influences such as sand, gravel and clay mining industries or nuclear power would have large effects on nature and could potentially push nature over irreversible thresholds. One German interviewee even opted for the unstable balance, indicated by decreasing biodiversity. Among Dutch interviewees the balance in nature views were more divers. While two Dutch interviewees choose the buffered balance, using similar arguments as the German interviewees, the other four Dutch interviewees choose the stable balance and the indifferent balance, arguing that nature will always remain. One interviewee mentioned the indifferent balance, but did not want to make a decision for one depiction.

The human-nature relationship showed more consensuses across interviewees from the two countries. Most interviewees mentioned Participation and Partnership as the most desirable relationships. No interviewee picked Mastery over nature as most desirable. The perceived reality for the German and most Dutch actors was Mastery over nature, while two Dutch interviewees opted for Partnership.

\subsection{Experiences with Participation}

The actors' participatory experiences were diverse. Especially among German civil actors, various negative experiences with participatory practices prevailed, leading to frustration. Those experiences were characterised by unsuccessful attempts of civil actors to influence decisions. German storylines were connected to the 1993 and 1995 near-catastrophic flood events and the interactions with the relevant authorities during that time. Interviewees felt that German authorities at the time denied the arrangement of an emergency polder to protect more densely populated areas elsewhere. They felt that the authorities purposefully did not take 
measures to protect important economic and societal developments in the cross-border region. Dutch interviewees also referred to the events from the 1990s, but with less negative associations. Dutch interviewees also mentioned experiences in the sounding board in which different actors positively interacted.

\subsection{Factors for Successful Participation}

\subsubsection{Trust}

Especially among German civil actors, lack of trust towards the government and the negative relationships with other actor groups became apparent through relationship frames and through experiences connected to the 1993 and 1995 floods. Dutch civil actors mentioned that overall, they trusted the governmental strategy and that the government was capable of dealing with the issue. On a local scale the civil actors came up with alternative plans, but this did not seem to affect their overall trust in the governmental bodies.

Dutch interviewees mentioning the events from the 1990s or the emergency polder did not lament that relationships had suffered as a result of the events. A member of the Dutch citizen initiative against the plans of the Ooij emergency polder felt there was transparency from Dutch authorities in regard to flood safety plans, and a nature organisation actor remembered the help the military provided during the 1990s events as well-organised and functioning.

\subsubsection{Motivations}

Civil actors in both countries were often driven by personal motivations, and either generally concerned about flood safety in their area or directly affected by management measures. For Germans, the motivation stemmed from distrust or fear that the German flood management strategy was either non-existent or steered too much by economic motivations (e.g. agricultural businesses with traditional views and municipalities concerned with their popularity among voters). Dutch civil actors opposed local measures, but also felt a civic responsibility to be involved in democratic processes. Interviewees from nature organisations, especially in Germany, grounded their motivations to participate in river management in a passion for nature formed through experiences with nature. They mentioned growing up at the North Sea or playing in the river landscape, bonding with nature as a child, and an early interest in shipping and technology.

\subsubsection{Expectations}

Looking back at cognitive frames and experiences, many expectations towards river governance projects become apparent. German actors wish for direct involvement at an early stage in the visioning process and more positive interactions on platforms that facilitate social learning and trust building, while the Dutch civil actors would like to be directly involved in local projects that affect them.

Various bypasses and nature development projects were mentioned as illustrations of good water management strategies on both sides of the border. Dutch interviewees mentioned the Nijmegen bypass and smaller natural bypasses. German interviewees positively mentioned the German renaturation project in Ansberg along the Ruhr (a Rhine tributary) and the Rhine flood channel by Rees as good flood risk management. Some German interviewees referred to 
examples in the Netherlands. References towards these projects show that interviewees would expect similar developments in the cross border region in the coming years.

\section{Discussion}

This study explored cognitive perceptions towards participation, cultural belonging, nature views and previous experiences with river management. Stemming from the similarities and differences found between civil actors from citizen initiatives and nature organizations in Germany and the Netherlands, we formulate barriers and opportunities for river governance in the cross-border region Rhine-Waal.

All interviewees agreed that more innovative river management is needed, both regarding organisational and technical aspects. On the organisational side, actors wanted innovation regarding public involvement and governance. On a technical side, actors asked for more innovative and combined solutions such as keeping fields wet in spring to maintain bird habitats and reduce flood risks, or building channels between large economic areas to reduce shipping pressure on the Rhine. However, there were clear differences between issue frames (perceived problems) between the two countries and also the two types of actor groups. Scholars have shown that this can lead to a misalignment of the actors' focus in transnational settings, leading to miscommunications and conflicts in environmental negotiations (Doorn 2016; Lewicki et al. 2003; Mostert 2003b). German citizen initiatives, concerned with flood safety, and German nature organisations concerned with naturalness and biodiversity currently do not interact in participatory processes, and do not share or seem to have interest in each other's views. Acknowledging both issue frames is necessary for successful future cooperation. Dutch actors, who were much more aware of benefits of an integration of aims (Fliervoet and van den Born 2017), could stimulate this idea among German actors by providing positive examples of cooperation in the visioning process. The transnational cooperation provides an opportunity for social learning and alignment of frames towards a common goal. While interviews showed that there is potential for an integration of aims on the German side e.g. by improving bird habitat through water retention, these views are not accepted by all stakeholders. At the same time, the strong view of German nature organisations can be seen as an opportunity in itself, as it could lead to more pristine and wild nature development being integrated into Dutch river management. For both these aspects, an open minded visioning process is essential.

The actors' perceived roles were similar among countries and actor groups. This indicates that the organisations could align their aim and participatory focus, providing opportunity for transnational cooperation. However, the relationships with other actors were dramatically different between the two countries. Consequently, the processes of participation reflect these different relationships. Especially in Germany the lack of trust between actors, negative relationships and low participatory involvement characterize the political landscape and create the potentially largest hurdles for transnational governance. German citizens have little possibilities to participate early on in visioning processes, making it difficult to progress towards trust building or social learning experiences for either civil actors or the government (Pahl-Wostl et al. 2008). A vicious circle is maintained, in which distrust and negative experiences lead to increasingly negative relationships that cause further distrust. It seems that a shift towards more bottom-up governance is urgently needed, as current practices inhibit participatory processes (Tippett et al. 2005). This is a paradox, as most German actors asked for direct bottom-up participation but also acknowledged that a national authority would be needed to resolve deadlock situations between interest groups. 
Nonetheless, actors' concerns must be heard and their expectations and visions must be incorporated into the process to build trust. One example of how this could be initiated is with a Joint Planning Approach (JPA). JPA anticipates unavoidable conflict, but allows stakeholders to collaborate through interaction, setting realistic expectations, mutual learning, joint visioning and exploration (Warner and de Groot 2011). Sounding boards and multi-stakeholder platforms fostering cooperation are essential for citizen initiatives to contribute to water management in Germany and The Netherlands. While some researchers indicate that sounding boards exist in Germany, they criticize the lack of citizen representation within these boards (Albrecht 2013; Bormann et al. 2012). This matches the perceived lack of citizen participation in Germany by our interviewees. The interviewees prefer a top-down authority that makes use of bottom-up approaches. Again this would advocate to adopt a JPA (Warner and de Groot 2011), because JPA aims to find a balance between unavoidable top-down planning and bottom-up approaches.

While all actors perceived cultural differences, none of the actors perceived these differences to complicate transnational cooperation between civil actors. However, underlying cultural differences should not be neglected as governmental cooperation has shown to cause difficulties between formal procedures of Germans and trial-and-error approaches of Dutch actors (Wiering et al. 2010). The progressive mind-set of the Dutch and the long history with river management caused a shift towards Room for the River measures and more innovative forms of land use along the river. This shift has yet to commence in the rural parts of the German lower Rhine region. Even though this appears as a barrier for transnational cooperation, it should be seen as an opportunity, in which rural inhabitants are introduced to Dutch examples of IRBM with less hierarchical structures.

Scholars have indicated that perceptions of nature influence preferred water management styles (Verbrugge et al. 2013). One clear difference between actors was visible regarding perceptions of nature. While Dutch actors showed a tendency to perceive nature as everything around them, German participants had a vision of more autonomous, wild and pristine nature. This aligns with the German nature organisations' problem perception, which is largely focussed on nature protection and development. In previous studies on governmental actors, a similar tendency was found in discourses of river management (Renner and Meijerink 2017; Wiering et al. 2010). The fact that German civil actors mostly opted for protection measures without benefits for nature can be explained in two ways: either their large concern for safety and high risk perception emotionally overruled their preferences for nature (Slovic 1999) or the low number of German projects that integrate nature objectives and flood safety measures had not given them ideas for reconciliation of the two aspects. The perception of balance in nature and human-nature relationships was quite unanimous among all actors. The actors acknowledge the human influence on nature and the limitation of nature's resilience and opted mainly for the buffered image. Human-nature relationship views were also similar among actors with Mastery being seen as presently prevalent and the Participant or Partner as being most desirable. This similarity in perception creates opportunities for an alignment of transnational river management styles.

\section{Conclusion and Recommendations}

This case study has shown that future transnational river management in the cross-border region Rhine-Waal should consider the role of trust, participant motivations and expectations. We provided specific insights into cognitive perceptions, perceived cultural differences and nature views, but also previous experiences that shaped the actors. The complexity of views reinforces 
the importance of participatory governance in which these views are acknowledged. This would also facilitate implementation due to increased public acceptance (Wiering et al. 2010). With our novel multi issue and multi stakeholder approach comparing civil actor groups with each other and with their transnational counterparts, we indicated that the transnationality can provide opportunities for civil actors and their influence: German CIs did not find allies amongst other German groups, but could gain support and align with the views of their counterparts abroad.

All actors perceive future cooperation between the two countries as beneficial and as a learning process for implementing participation in the context of IRBM. The actors in both countries perceive their roles in participation similar which provides common ground for collaboration. The ideal balance of nature and human-nature relationships of the actors are in line with each other, offering opportunities for alignment of transnational river management styles. However, this study also showed different views on participation between the two countries with regard to problem definition, nature perception and perceived relationships and trust between governmental organisations on the one hand and civil actors on the other hand. Cultural differences, such as the progressive and innovative Dutch mindset and the German tendency to adhere to power structures and be risk averse might cause misalignment. To address these barriers, we argue that the actors could benefit from the establishment of a cross border learning environment, such as a living lab. A living lab approach facilitates an open innovation platform involving public organisations, private organisations, knowledge institutes and citizens to a research and development process at a geographically fixed location in which common visions and needs can be aligned and feedback towards the innovation process can be provided (Ståhlbröst and Holst 2012). Discussing the variety of different opinions and ideas in an open learning environment can help actors to be open towards and understand each other's views, which is a prerequisite for alignment of frames and transnational collaboration in the context of integrated river basin management. However, to reach this point, the government needs to adapt their role (see Grotenberg and Altamirano 2017). Legislation such as the WFD could help with this transition. The findings of this research, complemented by research of other actor groups (Wiering et al. 2010; Renner et al. 2017; Renner and Meijerink 2017; van Eerd et al. 2017), can facilitate shaping participatory approaches in the process of climate adaptation of the cross-border region, and help to overcome differences between actor groups.

Acknowledgements We like to thank Wessel Ganzevoort for his thorough language suggestions and comments that helped improve the manuscript.

\section{Compliance with Ethical Standards}

\section{Conflict of Interest None}

Open Access This article is distributed under the terms of the Creative Commons Attribution 4.0 International License (http://creativecommons.org/licenses/by/4.0/), which permits unrestricted use, distribution, and reproduction in any medium, provided you give appropriate credit to the original author(s) and the source, provide a link to the Creative Commons license, and indicate if changes were made.

\section{References}

Albrecht J (2013) The Europeanization of water law by the water framework directive: a second chance for water planning in Germany. Land Use Policy 30:381-391. https://doi.org/10.1016/j.landusepol.2012.04.009 
Andrews E, Weaver A, Hanley D, Shamatha J, Melton G (2005) Scientists and public outreach: participation, motivations, and impediments. J Geosci Educ 53(3):281-293

Ansell C, Gash A (2008) Collaborative governance in theory and practice. J Public Adm Res Theory 18(4):543571

Antonini M, Hogg MA, Mannetti L, Barbieri B, Wagoner JA (2015) Motivating citizens to participate in public policymaking: identification, trust and cost-benefit analyses. Journal of Social and Political Psychology 3: 131-147. https://doi.org/10.5964/jspp.v3i2.408

ATLAS.ti Version 7.0 [Computer sofware] (2016) Berlin, Scientific Sofware Development

Bormann H, Ahlhorn F, Klenke T (2012) Adaptation of water management to regional climate change in a coastal region - hydrological change vs. community perception and strategies. J Hydrol 454-455:64-75. https://doi.org/10.1016/j.jhydrol.2012.05.063

Central Commission for the Navigation of the Rhine (CCNR) (2016) Information on the waterway Rhine. http://www.ccr-zkr.org/12030100-en.html. Accessed 08 Oct 2017

Creed WE, Langstraat JA, Scully MA (2002) A picture of the frame: frame analysis as technique and as politics. Organ Res Methods 5:34-55. https://doi.org/10.1177/1094428102051004

de Vente J, Reed M, Stringer L, Valente S, Newig J (2016) How does the context and design of participatory decision making processes affect their outcomes? Evidence from sustainable land management in global drylands. Ecol Soc 21(2):24. https://doi.org/10.5751/ES-08053-210224

Dewulf A, Gray B, Putnam L, Lewicki R, Aarts N, Bouwen R, van Woerkum C (2009) Disentangling approaches to framing in conflict and negotiation research: a meta-paradigmatic perspective. Human Relations 62:155-193. https://doi.org/10.1177/0018726708100356

Doorn N (2016) Governance experiments in water management: from interests to building blocks. Sci Eng Ethics 22:755-774. https://doi.org/10.1007/s11948-015-9627-3

Fliervoet JM, van den Born RJG (2017) From implementation towards maintenance: sustaining collaborative initiatives for integrated floodplain management in the Netherlands. International Journal of Water Resources Development 33:570-590. https://doi.org/10.1080/07900627.2016.1200962

Fliervoet JM, Van den Born RJG, Smits AJM, Knippenberg L (2013) Combining safety and nature: A multistakeholder perspective on integrated floodplain management. J Environ Manag 128:1033-1042.

Gibbs GR (2007) Analyzing qualitative data. SAGE Publications Ltd, London

Grotenberg S, Altamirano M (2017) Government facilitation of external initiatives: how Dutch water authorities cope with value dilemmas. International Journal of Water Resources Development. https://doi.org/10.1080 $/ 07900627.2017 .1374930$

Hofstede G (2011) Dimensionalizing cultures: the Hofstede model in context. Online Readings in Psychology and Culture 2(1). doi:https://doi.org/10.9707/2307-0919.1014

Hooghe M (2003) Participation in voluntary associations and value indicators: the effect of current and previous participation experiences. Nonprofit Volunt Sect Q 32:47-69. https://doi.org/10.1177/0899764003251198

Hulbert M, Gupta J (2015) The split ladder of participation: a diagnostic, strategic, and evaluation tool to assess when participation is necessary. Environ Sci Policy 50:100-113. https://doi.org/10.1016/j. envsci.2015.01.011

Joint Nature Conservation Committee (2010) EU Water Framework Directive. http://jncc.defra.gov.uk/page1375. Accessed 08 Oct 2017

Junier SJ, Mostert E (2012) The implementation of the water framework directive in the Netherlands: does it promote integrated management? Phys Chem Earth 47-48:2-10. https://doi.org/10.1016/j.pce.2011.08.018

Kim S (2010) Public trust in government in Japan and South Korea: does the rise of critical citizens matter? Public Adm Rev 70:801-810. https://doi.org/10.1111/j.1540-6210.2010.02207.x

Lewicki RJ, Gray B, Elliot M (2003) Making sense of intractable environmental conflicts. Island Press, Washington

Mostert E (2003a) The challenge of public participation. Water Policy 5:179-197

Mostert E (2003b) Conflict and cooperation in the management of international freshwater resources: a global review. Delft University of Technology, Delft

Mostert E, Pahl-Wostl C, Rees Y, Searl B, Tàbara D, Tippett (2007) Social learning in European river-basin management: barriers and fostering mechanisms from 10 river basins. Ecol Soc 12(1):19

Pahl-Wostl C, Tàbara D, Bouwen R, Craps M, Dewulf A, Mostert E, Ridder D, Taillieu T (2008) The importance of social learning and culture for sustainable water management. Ecol Econ 64:484-495. https://doi. org/10.1016/j.ecolecon.2007.08.007

Reed MS (2008) Stakeholder participation for environmental management: a literature review. Biol Conserv 141: 2417-2431

Renner T, Meijerink S (2017) Policy entrepreneurs in international river basins - getting climate adaptation on the cross-border water policy agenda. Reg Environ Chang. https://doi.org/10.1007/s10113-017-1178-5 
Renner T, Meijerink S, van der Zaag P (2017) The evolution of regional cross-border water regimes, the case of Deltarhine. J Environ Plan Manag. https://doi.org/10.1080/09640568.2017.1371005

Rijke J (2012) Room for the river: delivering integrated river basin management in the Netherlands. International Journal of River Basin Management 10(4):369-382. https://doi.org/10.1080/15715124.2012.739173

Rubin HJ, Rubin IS (1995) Choosing interviewees and judging what they say. In: qualitative interviewing. The art of hearing data. SAGE Publications Ltd, Thousand Oak

Siddiki S, Jangmin K, Leach WD (2017) Diversity, trust, and social learning in collaborative governance. Public Adm Rev 77(6):863-874 doi.org/10.1111/puar.12800

Slovic P (1999) Trust, emotion, sex, politics, and science: surveying the risk-assessment battlefield. Risk Anal 19:689-701. https://doi.org/10.1023/A:1007041821623

Smits AJM (2009) 'WaalWeelde': van onderaf werken aan ruimtelijke kwaliteit en duurzame veiligheid ['WaalWeelde': a bottom-up approach towards spatial quality and flood safety]. Vakblad Natuur Bos en Landschap 6:6-8

Ståhlbröst A, Holst M (2012) Living lab methodology handbook. Luleå University of Technology and CDT, Luleå

Thomas F, Knüppe K (2016) From flood protection to flood risk management: insights from the Rhine river in North Rhine-Westphalia, Germany. Water Resource Management 30:2785-2800. https://doi.org/10.1007 /s11269-016-1323-9

Thompson M (2003) Cultural theory, climate change and clumsiness. Econ Polit Wkly 38:5107-5112. https://doi.org/10.2307/4414349

Tippett J, Searle B, Pahl-Wostl C, Rees Y (2005) Social learning in public participation in river basin management - early findings from Harmoni COP European case studies. Environ Sci Policy 8:287-299 doi.org/10.1016/j.envsci.2005.03.003

van den Born RJG (2008) Rethinking nature: public visions in the Netherlands. Environmental Values 17(1):83109. https://doi.org/10.3197/09632708X271969

van Eerd M, Wiering M, Meijerink S (2014) Integrated, transboundary climate-adaptation governance. Exploring essential steps for the development of a cross-border and integrated climate-adaptation strategy. Radboud University, Nijmegen. https://doi.org/10.13140/RG.2.1.2799.7201

van Eerd M, Wiering M, Dieperink C (2017) Solidarity in transboundary flood risk management: a view from the Dutch North Rhine-Westphalian catchment area. Clim Pol 17(3):261-279. https://doi.org/10.1080 /14693062.2015.1075376

Verbrugge LNH, van den Born RJG, Lenders HJR (2013) Exploring public perception of non-native species from a visions of nature perspective. Environ Manag 52(6):1562-1573. https://doi.org/10.1007/s00267-0130170-1

Verbrugge LNH, Ganzevoort W, Fliervoet JM, Panten K, van den Born RJG (2017) Implementing participatory monitoring in river management: the role of stakeholders' perspectives and incentives. J Environ Manag 195: 62-69. https://doi.org/10.1016/j.jenvman.2016.11.035

Wang Z-Y, Lee JHW, Melching CS (2015) Integrated river management. River Dynamics and Integrated River Management 1:725-800. https://doi.org/10.1007/978-3-642-25652-3_12

Warner J, de Groot (2011) Joint River planning: striking a balance between justifiable technocracy, desired collaboration and unavoidable conflict. In: de Groot W, Warner J (eds) The social side of river management. Nova Publishers, New York

Wiering M, Verwijmeren J, Lulofs K, Feld C (2010) Experiences in regional cross border co-operation in river management. Comparing three cases at the Dutch-German border. Water Resour Manag 24:2647-2672. https://doi.org/10.1007/s11269-009-9572-5 